\title{
Strategy for separation and treatment of disaster waste: a manual for earthquake and tsunami disaster waste management in Japan
}

\author{
Misuzu Asari · Shin-ichi Sakai · Toshiaki Yoshioka • \\ Yasumasa Tojo $\cdot$ Tomohiro Tasaki • \\ Hidetaka Takigami · Kohei Watanabe
}

Received: 22 November 2012/ Accepted: 5 June 2013/Published online: 25 June 2013

(C) The Author(s) 2013. This article is published with open access at Springerlink.com

\begin{abstract}
Shortly after the March 11th earthquake and tsunami in eastern Japan, a Task Team for Disaster Waste Management and Reconstruction was established within the Japan Society of Material Cycles and Waste Management (JSMCWM). One of the major tasks undertaken by the team was to create a manual entitled, Strategies for Separation and Treatment of Disaster Waste. In this paper, this JSMCWM manual is introduced, followed by a review of existing guidelines for disaster waste management in various countries. We identify useful guidelines created by international agencies, national and local governments. The JSMCWM manual adds our new experiences, especially characterized by a huge scale of disaster and tsunami information, to the existing knowledge with an emphasis on separation and subsequent treatment options. It should be desirable to share our knowledge and experiences, not only domestically but also with other countries in the world, especially regions that could be affected by large earthquake and tsunami events.
\end{abstract}

\footnotetext{
M. Asari $(\bowtie) \cdot$ S. Sakai

Kyoto University Environment Preservation Research Center, Yoshida Honmachi, Sakyo-ku, Kyoto 606-8501, Japan

e-mail: misuzuasari@eprc.kyoto-u.ac.jp

T. Yoshioka

Tohoku University, Sendai, Japan

Y. Tojo

Hokkaido University, Sapparo, Japan

T. Tasaki $\cdot$ H. Takigami

National Institute for Environmental Studies, Tsukuba, Japan

K. Watanabe

Teikyo University, Itabashi, Japan
}

Keywords Disaster waste $\cdot$ Manual $\cdot$ Separation . Recycling $\cdot$ Tsunami

\section{Introduction}

Guidelines for managing disaster waste

Many countries have experience in dealing with huge natural disasters, such as the Sumatra earthquake of 2004, the devastating floods caused by Hurricane Katrina in the United States in 2005, the Haiti earthquake in 2010, and the floods in Thailand in 2011. Such disasters have always happened and will continue to do so. A necessary task in the early recovery phase is the removal of disaster waste (e.g. rubble). Such waste can overwhelm the capacity of existing facilities and have a negative influence on other emergency response and recovery activities. At the time of a disaster, planners must determine the quantity of waste generated, gather it in temporary storage sites, and select and arrange for appropriate disposal or recycling options. Because it can be hard to do these things during a state of emergency, it is important that we envisage such scenarios when times are normal and prepare plans or guidelines for performing these tasks. However, we currently have few guidelines for selecting management options [1] in extreme disasters.

Purpose of this paper

Although guidelines for disaster waste management exist in Japan and the rest of the developed countries, developing countries have almost no plans beyond those created by international aid organizations. Such plans that do exist need to be customized to suit each country's situation. It is 
particularly important to discuss and identify the kinds and characteristics of the disasters that could affect each country, along with the available waste disposal or recycling options and the priority countermeasures.

Here, to share our knowledge of disaster waste management, we introduce Strategies for Separation and Treatment of Disaster Waste. This manual was written by our group at the Japan Society of Material Cycles and Waste Management (JSMCWM) to guide the management of the disaster waste generated from huge earthquakes and tsunamis in Japan. First, we review several international and United States guidelines as existing models of disaster waste management. Second, we introduce the procedures used to write the manual and outline its contents. Finally, we discuss tasks for future studies and practices.

\section{Review of existing guidelines for managing disaster waste}

Different contexts of disaster waste management

Guidelines for effective disaster waste management are best made under normal, non-disaster, conditions. However, developing countries and local governments do not need to formulate complete plans from scratch. Realistically, after reviewing existing guidelines, they can establish a simple plan and gradually revise it to suit their own circumstances.

The most important point in making disaster waste management more effective is to understand the purpose and background of such management. For this reason, we review some background disaster waste management strategies from around the world [2], below.

The first important point in addressing disaster waste issues on a global scale is that disasters generate a wide range of wastes. These include not only wastes from natural disasters such as earthquakes, tsunamis, floods, wildfires, and wind damage by typhoons or hurricanes, but also wastes generated by humans through disputes (e.g., unexploded shells requiring very careful disposal). Because the nature of each disaster differs, the disposal lead time, waste condition, and disposal difficulty also differ. That said, there are also similarities in waste disposal in terms of global experiences.

The second point is that in some developing countries a legal framework for disaster waste management is not available, or there is a lack of financial, technical, and institutional capacity to enforce the existing legal framework. This is quite different from the situation in Japan or in other developed countries, where a legal framework does exist to deal with emergencies, and the government, to a variable extent, plays a management role (although those local governments affected by the disaster may not be able to function).

The third point is that situations vary from country to country. The condition and distribution of waste production and disposal facilities in each country are unique; moreover, variations in human resources and funding leave a large range of options, and institutional arrangements for managing disaster waste vary across countries. In most countries, a disaster management department or agency takes the lead after a disaster occurs, and that agency works with related ministries, including local governments, for disaster waste management or removal. However, in the first two steps (prevention and preparedness) and the last step (recovery), the relevant ministry or local government takes the lead.

Finally, management plans are greatly influenced by commonly accepted ideas of waste disposal and the roles of stakeholders (i.e., by cultural aspects). Below, we examine the contents of several established guidelines from the perspective of these four points.

\section{Review of guidelines}

The United Nations Office for the Coordination of Humanitarian Affairs Environmental Emergencies Section's Disaster Waste Management Guidelines (UNOCHA guidelines) [3] were drawn up in 2011. They give a comprehensive and well-balanced explanation of the important components of debris management plans in terms of providing international assistance for stricken countries. These guidelines list three points as waste management objectives:

1. Minimize risks to human life and health

2. Reduce risks to the environment

3. Ensure that the realization of any of the values in the plan benefits the affected communities

The general guidance is divided into four phases: (1) emergency, (2) early recovery, (3) recovery, and (4) contingency planning. There are checklists, assessment sheets, and practical guidance for following the guidelines in each phase. Annexes to the guidelines include a needs-assessment sheet and waste-hazard ranking tool, a basic wastehandling matrix, guidelines for development and closure of temporary storage sites, a fundraising project template, and information on companies and support groups participating in the assistance.

The WHO Technical Notes on Drinking Water, Sanitation and Hygiene in Emergencies [4] present concrete points on the security of water and sanitation in emergencies. They contain many illustrations, definitions of technical terms, and a clear explanation of the objective of the plan, and are therefore suitable for beginners involved in 
waste management. The notes introduce methods of dealing with solid disaster waste (e.g. rubble) and excreta in terms of assistance for developing countries. Explanations of the importance of giving the victims tasks to perform, protecting the workforce, encouraging recycling, and explaining how to build a communal pit in which to dump waste are given in the pages on solid waste. For excreta disposal in emergencies, the notes explain how to formulate a disposal plan, the importance of telling people to defecate in designated areas to avoid polluting water and food, and the construction of various types of latrines. The notes also consider the needs of socially vulnerable people such as the physically disadvantaged.

OXFAM, an international nongovernmental organization that aims to alleviate poverty, also performs disaster relief and gives recovery assistance. OXFAM's Technical Brief [5] formalizes the components of various individual activities and gives five individual guidelines, for the management and disposal of evacuation shelter waste (1) and domestic waste (2), the management of human waste (3), the disposal of human waste (4), and for the removal of large amounts of disaster waste (5). As with the WHO Technical Notes, the OXFAM briefs are compiled in the context of assistance for developing countries. There are three unique aspects to the briefs: (1) they make it easy for a layman to comprehend the issue at stake by giving examples of the risks posed by improper waste disposal; (2) they describe the basic waste hierarchy (waste reduction and minimization, waste reuse and repair, and recycling); and (3) they give concise explanations, including illustrations, of the requirements for human-waste-disposal bags and for establishing pits (e.g., distance from water sources, depth, and fence construction) and urine-diversion toilets for emergency excreta disposal, as well as pit latrines. Supervisors and workers should find the OXFAM guidelines very useful for implementing relief and recovery plans.

In the United States there are both national- and statelevel guidelines. The Federal Emergency Management Agency's (FEMA) Public Assistance Debris Management Guide [6] gives information to state and local governments and private nonprofit organizations (NPOs) seeking to receive funds from the federal government for waste management. The guide has three parts: FEMA eligibility criteria, effective debris management planning concepts, and federal government operations in emergencies. Not only local administrative agencies but also private NPOs can apply for funds. Funding is a two-step process: the federal government gives the funds to the state and the state distributes the money to various state agencies, local governments, and private NPOs.

To encourage local communities to establish disaster debris management plans, the US Environmental
Protection Agency formulated Planning for Natural Disaster Debris in 1995 and revised it in 2008 [7]. The plan is based on various natural disasters experienced by the United States and notes planning considerations, implementation options, lessons learned from the past, and various resources for reference. The plan can be divided into three elements: pre-planning activities (affirmation of FEMA's requirement for public assistance eligibility, organization of a team for creating the plan, and establishment of a schedule for updating the plan); ancillary activities (identification of waste types and forecasting of the amounts, application of local environmental regulations, confirmation of the current capacity for waste management and identification of equipment, and development of a communications plan); and implementation (disaster waste removal, collection, management, recycling, and disposal). The plan sheds light on the need for environmental conservation and emphasizes the need for proper management of hazardous waste, selection of acceptable locations for storage or staging, appropriate use of available landfill capacity, and use of reuse and recycling opportunities to the fullest extent possible. It also summarizes seven past disaster cases and claims that the lessons learned from those experiences can enable us to minimize costly mistakes, expedite recovery, protect human health and the environment, and prevent the generation of additional waste by formulating a debris management plan before a disaster occurs. The plan emphasizes the importance of taking every issue into consideration, periodically updating the contents of any guidelines, and being fully prepared for disasters.

The California government's Integrated Waste Management Disaster Plan: Guidance for Local Government on Disaster Debris Management [8] is a huge set of guidelines that was compiled in 1997 and consists of 17 chapters and 465 pages. (It cites 50 other documents.) Its chapter headings are Government Coordination, Predisaster Assessment, Debris Management Programs, Temporary Storage Sites, Contracts, Reimbursement, Mutual Aid, Curbside Collection Program, Building Demolition program, Household Hazardous Waste Collection Program, Public Information Program, Rebuilding Using Recycled-content Products, Standardized Emergency Management System, the State Natural Disaster Assistance (NDAA) Program, the Federal Assistance Program, and Case Studies. The guideline is of practical use, and each chapter begins with a background explanation of the chapter's importance to disaster waste management. The main chapter content lists the steps that need to be taken to develop debris-management strategies, along with an explanation of each step and a checklist. 


\section{Procedures: compiling the JSMCWM manual}

\section{Establishment of the JSMCWM task team}

Japan's 11 March 2011 earthquake and tsunami made major news headlines in Japan and around the world. By 14 March, many young researchers at JSMCWM were already suggesting the need to establish a task team to tackle disaster waste. The Task Team on Disaster Waste Management and Reconstruction was established on 18 March after discussions and preparations within the Society. There has been active exchange of opinions and information through the website (http://eprc.kyoto-u.ac.jp/saigai/) and the mailing list.

Not only researchers but also private engineers, members of the public, and staff of local authorities-a total of more than 150 people-had joined the task team as of 31 March, 2012. The objectives of establishing the task team were:

1. Formation of an information platform for disasterwaste-related information.

2. Establishment of a wide social network for measures against disaster waste.

3. Derivation of basic knowledge for academic records of disaster waste and renewal of policies for taking measures against this waste.

One of the major tasks for the task team in the field and upon our return was to compile a manual, which was titled Strategy for Separation and Treatment of Disaster Waste. Among the many reasons for writing the manual, there were two main ones:

- There was a need to consolidate knowledge and wisdom to tackle the previously unexperienced volume and quality of tsunami waste.

- Sharing the good practices and issues faced by local authorities that were advanced in their waste treatment would contribute overall to reconstruction and help other authorities that were behind in treating their waste.

\section{Writing the manual}

We identified the required contents for the manual through discussions between members of the task force and stakeholders in the field at the disaster site and discussions held among task team members. The team then assigned one person who was responsible for each part of the manual. The drafts were discussed through the mailing list and edited to reflect these discussions. Finally, the chapters were compiled into one document. All of this work was done on a voluntary basis. The first version of the manual was released on 4 April 2011. The second version, which covered the whole process of waste management, including treatment and final disposal, was released on 30 April. All pages of the manual are available on the JSMCWM website. Moreover, a technical manual that incorporated information on prior planning was published as hard copy [2] in May 2012, and an English version was released on 1 December 2012 (http://eprc.kyoto-u.ac.jp/saigai/). These manuals focus mainly on earthquake- and tsunami-related disaster waste management.

\section{Results and discussion}

Outline and characteristics of the JSMCWM manual

The contents of the manual are shown in Table 1. It has a total of 104 pages in Japanese, and each chapter focuses on one aspect of waste treatment so as to address specific needs. There are other features designed for practical use (described below).

At this stage, the manual focuses on how we are tackling waste issues caused by the Great East Japan Earthquake. The three main targeted kinds of waste are:

- waste from evacuation shelters,

- earthquake waste,

- tsunami waste, which is waste resulting from and affected by the tsunami.

Radioactive contaminated waste (including contaminated general waste) generated by the accidents at the Fukushima nuclear power plant is not covered in the manual.

Characteristics of the manual are as follows:

- Even though the subject is disaster waste, recyclable items are listed to promote reuse and recycling to as great an extent as possible. The manual suggests methods of separation and options for reuse and recycling.

- The manual outlines the most practical hazardous and toxic waste countermeasures.

- The manual includes photos of good practices in disaster waste management.

Because the disaster generated a multitude of wastes, each type needs to be separated. Rubble (concrete and asphalt) and wood represent the largest volumes. The waste has to be separated into nonrecyclables and recyclables/ reusables, and attention needs to be paid to each individual component material. This will reduce the risks and likelihood of accidents associated with hazardous and toxic waste. 
Table 1 Contents of JSMCWS manual

\begin{tabular}{|c|c|}
\hline \multicolumn{2}{|l|}{ Outline } \\
\hline Guide 0 & Flow of measures and processes \\
\hline Guide 1 & Identification of category and sorting for disaster waste \\
\hline Guide 2 & Estimation of quantity generated \\
\hline Guide 3 & Phases of recovery or reconstruction and waste management \\
\hline Guide 4 & Flows for disaster waste separation and disposal \\
\hline Guide 5 & Planning of separation and disposal strategy \\
\hline Guide 6 & $\begin{array}{l}\text { 1. Removal of collapsed houses, etc. (Government guidelines) } \\
\text { 2. Selection and operation of temporary storage sites } \\
\text { 3. Selection and operation of storage sites } \\
\text { (primary and secondary waste storage sites) }\end{array}$ \\
\hline Guide 7 & $\begin{array}{l}\text { 1. An example of waste sorting: Waste management in evacuation shelters } \\
\text { 2. Examples of separation - garbage from temporary } \\
\text { accommodation facilities, household disaster waste, waste } \\
\text { soaked by tsunami, at emergency phase } \\
\text { 3. Examples of separation - tsunami debris and earthquake } \\
\text { rubble at early recovery phase } \\
\text { 4. Removal and separation of waste from collapsed houses } \\
\text { 5. Countermeasure against airborne dust using dust protective masks }\end{array}$ \\
\hline Guide 8 & $\begin{array}{l}\text { 1. Combustible mixed waste (Incineration) } \\
\text { 2. Desalting waste wood soaked in seawater } \\
\text { 3. Waste wood (reuse, recycle) } \\
\text { 4. Tsunami sediment } \\
\text { 5. Marine industrial waste } \\
\text { 6. Concrete and asphalt } \\
\text { 7. Tires } \\
\text { 8. Home appliances designated by the Recycling Law } \\
\text { 9. Other electronic appliances } \\
\text { 10. Automobiles } \\
\text { 11. Motorcycles } \\
\text { 12. Boats and ships } \\
\text { 13. Asbestos } \\
\text { 14. Hazardous/dangerous articles } \\
\text { 15. Valuables and items of sentimental value } \\
\text { 16. Sewage wastewater }\end{array}$ \\
\hline Others & $\begin{array}{l}\text { Quick reference for handling disaster waste: Cautions for workers and volunteers } \\
\text { Reference information about dismantling of damaged automobiles (for businesses) } \\
\text { Asbestos manual } 1-5 \\
\text { Reference: National guidelines for waste management following the } \\
\text { Great East Japan Earthquake }\end{array}$ \\
\hline
\end{tabular}

For hazardous and toxic waste, the manual gives examples of treatment flows after separation. Assuming that volunteers and nonexperts are involved in the work, a quick reference guide to hazardous and toxic waste is attached.

Finally, the manual includes photos as practical examples (mostly of good practice) from this catastrophic earthquake. Some municipalities have experienced delays in dealing with the enormity of their problems. We expect that the manual will be a helpful reference to these bodies in moving forward.
Flows for disaster waste separation and disposal

Methods of separation and disposal for disaster waste vary with each category and type of waste and from region to region, so some processes may be unnecessary or impossible to use in some regions. However, the overall processes of disaster waste management must be kept in mind in the planning of separation or disposal strategies. A common understanding of the processes and the technical terms among the parties involved is vital to ensure smooth 


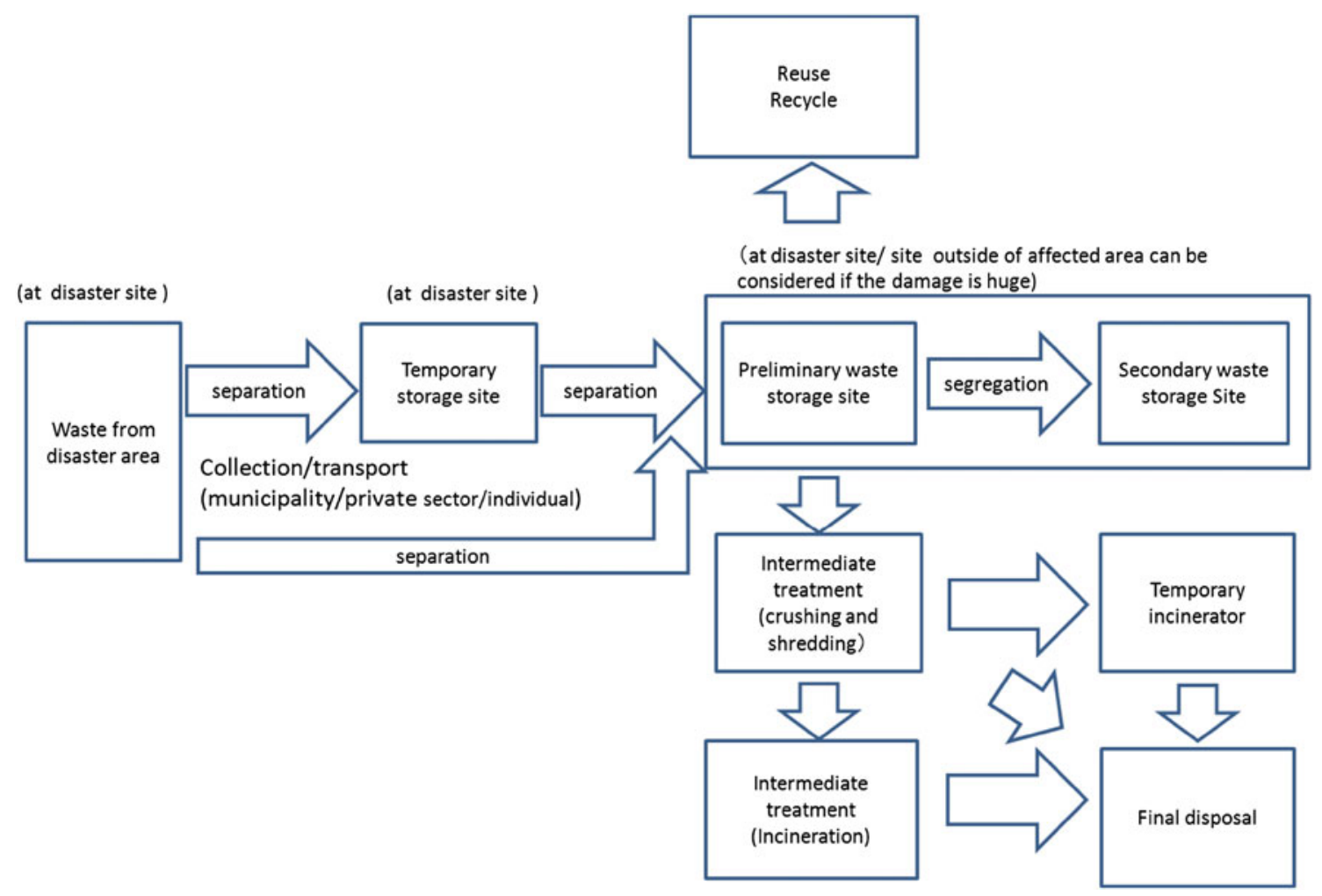

Fig. 1 Outline of the processes for separation and disposal of disaster waste

communication. Figure 1 outlines the processes used to separate and dispose of disaster waste.

After looking through the individual items described in the manual concerning possible methods of disposal (including reuse and recycling), each municipality should draw up a separation and treatment strategy according to at least the following criteria: prioritization of reuse and recycling; environmental protection; the need for recovery and reconstruction; the capacity of separation and treatment facilities; and cost.

Even for disaster waste, separation is possible. One example is given in Fig. 2 (also see Guide 7-2). Another example is given in Guide 7-4, where we discuss the removal of buildings destroyed by the tsunami. In that case, to the extent possible, materials were separated into (1) waste metals, (2) raw wood, (3) home appliances, (4) automobiles, (5) hazardous materials, (6) rubble (concrete and asphalt), (7) tatami floor mats and mattresses, and (8) valuables and items of sentimental value.

Separation is conducted not only at the removal or temporary storage site but also at the preliminary storage site. Treatment methods for recyclables, combustibles, hazardous waste, valuables and items of sentimental value, and tsunami sediment are introduced below.
Recycling

Basically, designated home appliances, automobiles, and personal computers are recyclable as determined by Japanese recycling laws.

For example, home appliances specified by the Electrical Home Appliance Recycling Law, such as televisions, air-conditioners, refrigerators, freezers, washing machines, and clothes dryers, should in principle be recycled (see Guide 8-8). If sorting is possible, these home appliances should be separated from other disaster waste and stored at temporary storage sites. Municipal staff then judge their recyclability (i.e. whether valuable resources can be recovered), taking into account the extent of damage and corrosion. If recycling seems possible, then the municipality brings the items to the producers' designated collection sites. (Under normal circumstances, these specified home appliances are recycled by two producer groups (A and B); basically, any post-disaster recycling is conducted by the same groups in the same manner.) If recycling is not possible, the items should be disposed of together with the other disaster waste. If it is difficult to assess recyclability, municipalities may contact the Association for Electric Home Appliances (Japan). 


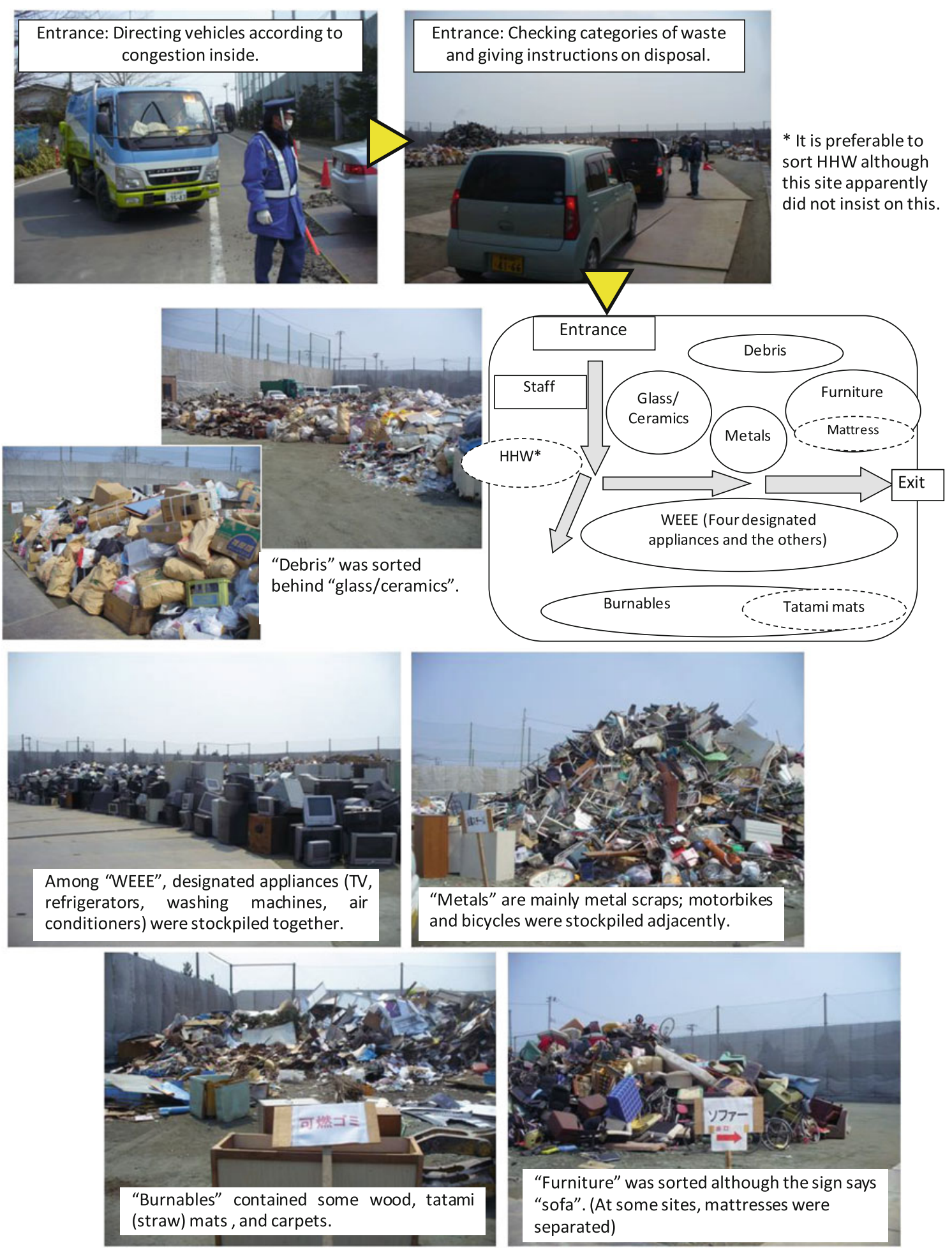

Fig. 2 Reference: A good example of management at a deposit (temporary storage) site for early recovery phase, Nipperia playground, Sendai city; workers direct and instruct how to sort and

Other than the items designated by the recycling law, metals, waste wood, concrete and asphalt, tires, motorcycles, boats, and ships can be reused or recycled. unload waste in drive-through style (Similar to deposit sites of municipalities in Western countries)

It is desirable to allow people the opportunity to recover items of personal and sentimental value (such as mortuary tablets or photo albums) and other valuables to the fullest 
extent possible. For example, these items can be handed into local government offices and owners should be given the chance to decide what to do with them. Workers must place valuables and memorabilia in safe-keeping, taking care not to damage them, whenever they find them while demolishing damaged houses. These sentimental items should be clearly distinguished from items that citizens themselves have brought because it is regarded as waste. If these items are dirty, attempts should be made to remove the dirt. Volunteers may be asked to do this work (see Fig. 3).

\section{Incineration}

In Japan, in the case of a serious disaster, incineration of mixed combustibles is important. Mixed waste is the waste remaining after the removal of reusable or recyclable and incombustible wastes. This mixed waste is then incinerated under appropriate combustion conditions, and the flue gas must be treated. Or, the mixed waste can be used for cement production, boilers, and blast-furnaces. However, the presence of chlorine (mainly from seawater) and foreign matter in the mixed waste may limit such utilization. In the case of long-term storage of unburned waste, due care must be taken to avoid ignition and fire. To protect public health and the environment, open burning of mixed waste is prohibited in principle.

\section{Hazardous waste}

Various products with harmful or dangerous characteristics may be mixed in with disaster waste. It is preferable to extract and separate these products to as great an extent as possible to ensure safe work, storage, and processing conditions. The manual describes hazardous/dangerous items (Guide 8-14) (also see Table 2) and asbestos (Guide 8-13) in detail. Hazardous/dangerous items should be appropriately stored at temporary storage sites until a proper treatment process can be established; many of these wastes do not require urgent treatment.
Tsunami sediment

Tsunami sediment is fundamentally sea-bed soil and sand that have been carried onshore by the tsunami. Depending on the circumstances of land use in the disaster area, various other objects and materials (i.e., wreckage) might have been mixed into it. Its composition and properties therefore tend to be diverse. We can perform a tentative zoning that reflects the risk inherent to tsunami sediment, considering the circumstances of land use and the characteristics of local facilities before the disaster. Zoning conducted in this manner and making use of this information can promote proper assessment, removal, and disposal of tsunami sediment. Removal and treatment of tsunami sediment must follow the procedures presented in Fig. 4 (also see Guide $8-4)$; the ultimate destiny of the sediment will depend on its composition and properties.

\section{Points to learn}

For some items, further work is required. The United Nations Environment Programme has produced a report that lists "learning points for Japan" [9]. These include (1) waste volume estimations, (2) waste transport, (3) land reclamation and landfilling, (4) handling of tsunami sediments, (5) management of hazardous materials, (6) environmental monitoring, (7) support of municipalities, (8) local employment generation, and (9) process optimization. The JSMCWM manual deals with many of these points and provides concrete guidelines. Below, they are discussed in three groups, namely waste volume estimation (point 1), management tools (points 2-6), and management systems (points 7-9). In addition, we note the importance of planning in advance of the occurrence of a disaster.

The information given below focuses on discussion and collaboration in an international context. The details of the issues may differ, depending on where the guideline will be implemented, be it in Japan, in other developed countries, or in developing countries.
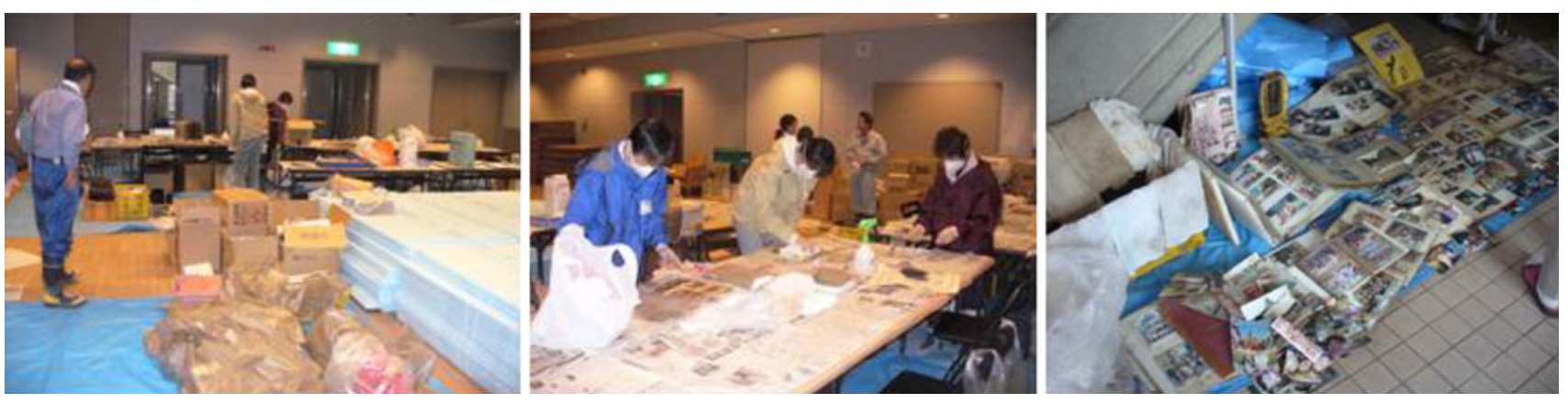

Fig. 3 Governmental staff of Sendai city collected valuables and memorabilia, storing them in a cultural center where volunteers removed dirt from them (April 23rd 2011, Sendai city). Items piled up at the entrance for checking (April 4th 2011, Sendai city) 
Table 2 Hazardous/dangerous products

\begin{tabular}{ll}
\hline Feature & Product \\
\hline Products containing hazardous substances & Agricultural chemicals, insecticides, and other chemicals (not home medicines) \\
& Coating medium, paint \\
& Batteries (Sealed type battery, Ni-Cd battery, micro cell, and car battery) \\
& Fluorescent lamps and mercury thermometers \\
Products having harmful/dangerous characteristics & Kerosene, gasoline, and engine oil \\
& Organic solvent (paint thinner, etc.) \\
& High-pressure gas cylinders \\
& Gas canisters, spray cans \\
Infectious waste from household & Fire extinguishers \\
\hline
\end{tabular}

Asbestos and waste electrical equipment containing chemicals like PCBs are handled in different sections of the manual

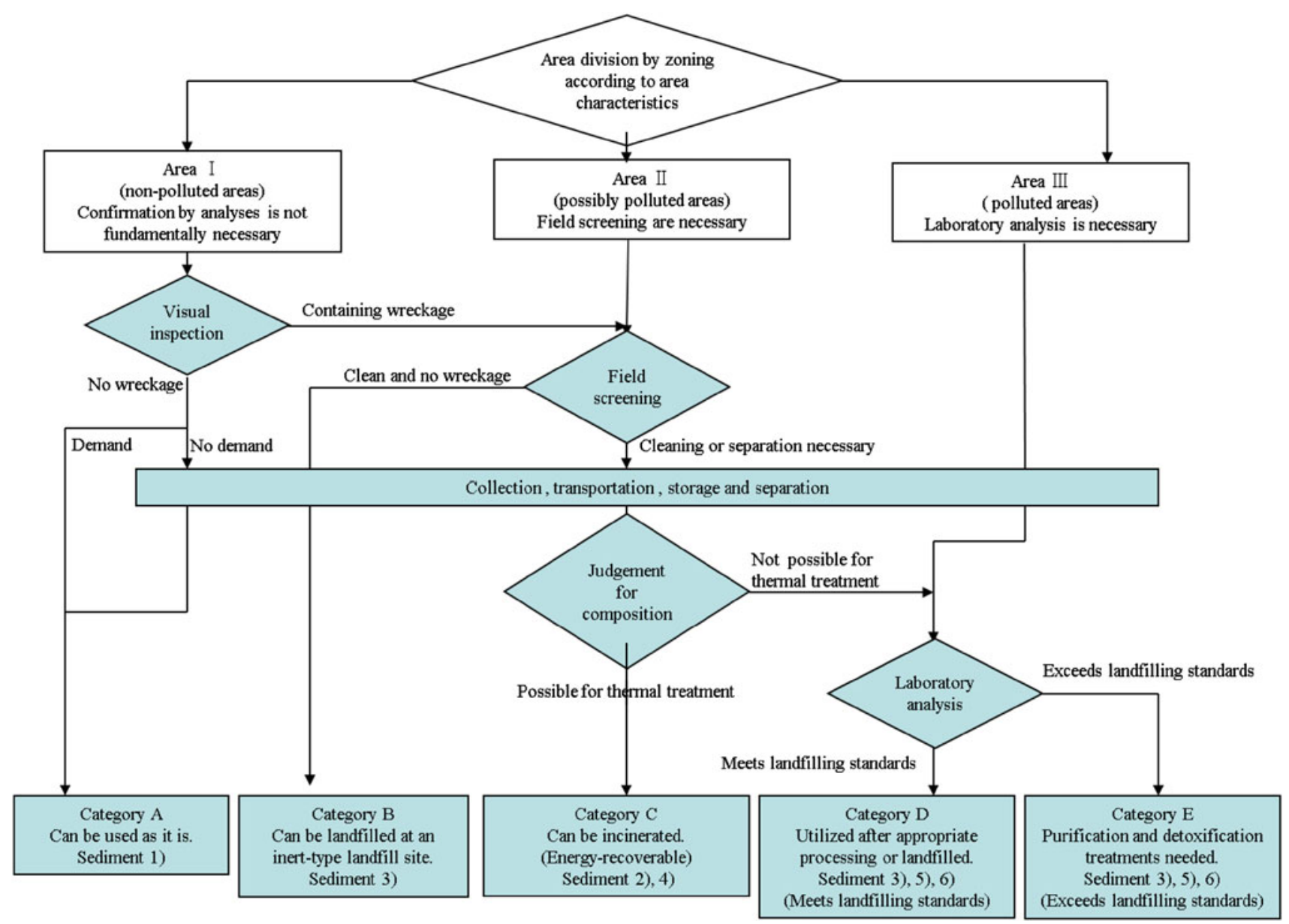

Fig. 4 Selection of removal and treatment methods for tsunami sediment

Estimation of the volume of disaster waste

Many guidelines include methods for estimating waste volume. However, these methods do not respond fully to the need for immediate estimates of the amount of disaster waste for each area (including the extent of damage to buildings and the types and amounts of waste generated). This information is required for smooth management of disaster waste in the emergency and early recovery phases of large-scale disasters. Satellite imagery, aerial photography, and GPS data can be used for this purpose, and we need to develop and share such estimation methods. 
Provision of satellite imagery and GIS software should prove be useful in developing countries.

Management tools

Many technical options for separation and subsequent treatment are given in the JSMCWM manual and in various other guidelines. For the sake of international dialogue, these options need to be characterized according to the technologies involved, the equipment needed, and the advantages and disadvantages. It would also be useful to discuss the criteria used for prioritization and decisionmaking in the choice of options. The JSMCWM manual is the first to include tsunami waste. It is important to check whether there are any other types of disasters that have not yet been discussed in such manuals.

\section{Management systems}

Issues regarding management systems vary greatly, depending on the country and locality. Discussions are currently ongoing in Japan, and the compilation of knowledge on these systems is a task for the near future. From an international perspective, the extraction of information useful for international assistance and cooperation will be important. Creation of a knowledge base on the regulations and systems on which assistance and cooperation will be based, along with discussions of coordination among donor countries, will be useful.

\section{Conclusion}

Here, we have introduced the JSMCWM disaster waste management manual and reviewed existing guidelines for disaster waste management in various countries. We have identified useful guidelines created by international agencies and national and local governments. The JSMCWM manual has added our new experience-especially in relation to the huge scale of the 2011 earthquake disaster and tsunami-to the existing knowledge bank, with an emphasis on separation and subsequent treatment options.
Being well-prepared for a disaster

This manual and the experiences gained in the tsunami aftermath should be useful in the future. Being prepared to cope with emergencies and natural disasters requires gathering basic knowledge, building the capacity of relevant organizations, and developing the ability to handle onsite issues. Many municipalities have already started reviewing their levels of preparedness. We would like to share our knowledge and experiences, not only domestically, but also with other countries, especially in regions that could be affected by large earthquakes and tsunamis.

Open Access This article is distributed under the terms of the Creative Commons Attribution License which permits any use, distribution, and reproduction in any medium, provided the original author(s) and the source are credited.

\section{References}

1. Brown C, Milke M, Seville E (2011) Disaster waste management: a review article. Waste Manage 31:1085-1098

2. Japan Society of Material Cycles and Waste Management (2012) The technical manual "Separation and treatment of disaster waste", Gyosei (in Japanese)

3. (2013) United Nations Office for the Coordination of Humanitarian Affairs Environmental Emergencies Section: Disaster Waste Management Guidelines. http://ochanet.unocha.org/p/Documents/ DWMG.pdf. Accessed 22 Apr 2013

4. WHO (2011) Technical Notes on Drinking-Water, Sanitation and Hygiene in Emergencies http://www.who.int/water_sanitation_ health/hygiene/envsan/technotes/en/

5. OXFAM Technical Brief. http://policy-practice.oxfam.org.uk/ publications/search? $\mathrm{i}=1 ; \mathrm{q}=* ; \mathrm{q} 1=$ publications; $\mathrm{q} 2=$ oxfam + technical + briefing +notes; $x 1=$ page_type; $2=$ series

6. US FEMA (2007) Public Assistance-Debris management guide. http://www.fema.gov/government/grant/pa/demagde.shtm

7. US EPA (2008) Planning for Natural Disaster Debris. http://www. epa.gov/osw/conserve/rrr/imr/cdm/pubs/pndd.pdf

8. California government (1997) Integrated Waste Management Disaster Plan: Guidance for local government on disaster debris management. http://www.calrecycle.ca.gov/disaster/disasterplan/

9. UNEP (2012) Managing post-disaster debris: the Japan experience. http://www.unep.org/pdf/UNEP_Japan_post-tsunami_debris.pdf 